\title{
EVALUACIÓN DEL GRADO DE INTERÉS DE LOS PRINCIPALES TURÍSTICOS DE LA CIUDAD DE CÓRDOBA
}

\author{
PROFA. DRA. ÁFRICA RUIZ GÁNDARA ${ }^{1}$ \\ UNIVERSIDAD DE SEVILLA \\ PROF. JOSÉ CARLOS CASAS DEL ROSAL ${ }^{2}$ \\ UNIVERSIDAD DE CÓRDOBA
}

\begin{abstract}
Resumen
La ciudad de Córdoba atesora una gran oferta turística cultural heredada de su importancia a lo largo de la historia. En ocasiones, esta riqueza cultural, es, al menos parcialmente, desconocida por el visitante. En este trabajo, hemos analizado en profundidad el interés suscitado por trece atractivos turísticos de la ciudad, mediante un cuestionario en escala Likert, al que se ha añadido información sociocultural a partir de una muestra de los turistas que visitaron la ciudad a principios de 2016. De igual modo, se realizaron comparaciones que permitieron analizar las diferencias en el grado de interés en función de las características sociodemográficas del entrevistado.
\end{abstract}

Palabras clave: Córdoba, atractivos turísticos, grado de interés, Likert

\section{Abstract}

The city of Córdoba displays a great cultural offer inherited from its importance through history. This cultural richness is sometimes unknown by the turist. In this workpiece, we have analyzed deeply the interest aroused by thirteen appealling attractions of the city, using a questionare base don Likert scale to which sociocultural infomation has been added from a simple of the tourists who visited the city at the beginning of 2016. Consequently, some comparisons are made to analyze the differences in the degree of interest according to the sociodemographic characteristics of the interviewee.

Keywords: Córdoba, tourist attraction, degree of interest, Likert

\section{Introducción}

1 Área de conocimiento: Métodos cuantitativos para la Economía y Empresa. E-mail: africaruiz@us.es

${ }^{2}$ Departamento de Estadística, Econometría, Investigación Operativa, Organización de Empresas y Economía Aplicada. E-mail: jcasas@uco.es 
Debido a su importante papel en la historia, llegando a ser una de las ciudades más importantes del mundo, la ciudad de Córdoba, situada al sur de España, reúne un conjunto incomparable de monumentos y lugares de interés, que la convierten en un importante destino de turismo cultural de Europa.

Dentro del conjunto monumental que atesora, destaca como principal reclamo turístico de la ciudad, la Mezquita Catedral, patrimonio de la humanidad desde el año 1984, enclavada en interior del centro histórico de Córdoba, también reconocido con tal distinción desde 1994.

Sin embargo, esta riqueza cultural es, en muchas ocasiones, desconocida en parte por los turistas que recalan en la ciudad, que no ven en ésta, su principal destino en el viaje. Sin embargo, cuando la conocen en profundidad, esta percepción cambia, en muchos casos. Esta es, al menos, la opinión mayoritaria dada por los hosteleros de la ciudad, al ser consultados sobre esta cuestión, en un análisis previo de la situación.

Las respuestas dadas por los profesionales que están en continuo contacto con el turista que visita la ciudad, motivaron, por tanto, la realización de este estudio de campo que tenía como objetivo obtener información del visitante, analizando sus rasgos sociodemográficos y su interés por algunos de los principales atractivos turísticos de la ciudad, así como por algunos atractivos típicos del país como son el flamenco o la fiesta taurina.

El grado de interés mostrado por los turistas que visitan la ciudad de Córdoba, puede servir para orientar la forma en el que realizar la promoción de la ciudad, tratando, por un lado, de fomentar aquellos atractivos por los que el visitante muestra mayor interés, y, por otro lado, analizar los motivos por los que otro atractivo turístico despierta un menor interés, con el fin último de promover acciones que inviertan este resultado.

\section{Turismo}

El concepto de turismo ha sido estudiado desde diversas disciplinas y desde numerosos puntos de vista en las mismas, debido a su complejidad. La definición adoptada por la Organización Mundial de Turismo en 1994 es: "El turismo comprende las actividades que realizan las personas durante sus viajes y estancias en lugares distintos al de su entorno habitual, por un período de tiempo consecutivo inferior a un año, con fines de ocio, por negocios y otros”.

No obstante, a lo largo de la historia la definición de turismo ha ido evolucionando hasta la actualidad.

En el período comprendido entre el final de la primera guerra mundial y el principio de la segunda, el turismo despierta el interés de los académicos. Durante este período, comienzan a publicarse los primeros trabajos en este campo, destacando la denominada escuela berlinesa, en la que destacan autores como Glucksmann, Schwinck o Bormann.

En 1942, los profesores de la Universidad de Berna, Hunziker and Krapf (1942), definen el turismo como: "la suma de fenómenos y de relaciones que surgen de los viajes y de las estancias de los no residentes, en tanto en cuanto no están ligados a una residencia permanente ni a una actividad remunerada”

En de Arrillaga (1955), se define al turismo como: "todo desplazamiento temporal, determinado por causas ajenas al lucro, el conjunto de bienes, servicios y 
organización que en cada nación determinan y hacen posible esos desplazamientos, y las relaciones y hechos que entre estos y los viajeros tienen lugar.”

De la Torre Padilla (1980), en su obra: El Turismo, Fenómeno social, aporta una nueva definición: "El turismo es un fenómeno social que consiste en el desplazamiento voluntario y temporal de individuos o grupos de personas que, fundamentalmente por motivos de recreación, descanso, cultura o salud, se trasladan de su lugar de residencia habitual a otro, en el que no ejercen ninguna actividad lucrativa ni remunerada, generando múltiples interrelaciones de importancia social, económica y cultural".

Posteriormente, Burkart and Medlik (1981) definen el turismo como: "los desplazamientos cortos y temporales de la gente hacia destinos fuera del lugar de residencia y de trabajo, y las actividades emprendidas durante la estancia en esos destinos”.

De forma casi simultánea, Mathieson and Wall (1982), lo definen como: "El turismo es el movimiento temporal de la gente, por períodos inferiores a un año, a destinos fuera del lugar de residencia y de trabajo, las actividades emprendidas durante la estancia y las facilidades creadas para satisfacer las necesidades de los turistas”.

\section{La ciudad de Córdoba}

Córdoba tiene un emplazamiento único, en el sur de la península ibérica, a orillas del río Guadalquivir, y junto a los recursos mineros de Sierra Morena, lo que explica su antigüedad. Está enclavada en la zona centro de la provincia del mismo nombre. Tiene una superficie de 1255,24 km2, y un clima Mediterráneo, con inviernos relativamente suaves y veranos muy calurosos y secos. En 2016 contaba con una población de 326.609 habitantes, en ligero descenso en los últimos años. Es la tercera ciudad más grande y poblada de Andalucía tras Sevilla y Málaga, y la 12ª de España.

Fue capital del Califato Omeya de occidente, época de gran esplendor y de la que conserva un gran número de monumentos, entre los que destaca, el más importante, la Mezquita - Catedral de Córdoba. La fundación de la ciudad se atribuye a los cartagineses, denominada por entonces Kart Iuba.

Fue conquistada por el imperio romano en el año 152 a.C., y refundada por Claudio Marcelo, quien cambió su denominación por Corduba (Colonia Patricia), convirtiéndola en la capital de la Hispania Ulterior, y posteriormente de la Bética.

En la última etapa del dominio romano, la ciudad pierde su condición de capital de la Bética, en favor de Hispalis. Tras la caída del imperio romano, Córdoba fue invadida por los visigodos, aunque su historia fue relativamente corta. Tarik, en 711 lleva a cabo la invasión musulmana de la península ibérica.

El Alcázar visigodo se convirtió en la primera residencia de los altos cargos musulmanes. Años más tarde de la llegada de Tarik, Córdoba se había convertido, nuevamente en capital, en este caso de Al Andalus, iniciándose la construcción de palacios y edificios de gran renombre.

Durante la época de Abderramán III, nombrado califa en el año 929, Córdoba alcanzó el mayor esplendor de su historia, independizándose del Califato de Damasco. No obstante, esto significó el inicio de su larga decadencia, acentuada cuando en 1236 fue conquistada por los cristianos (Fernando III el Santo). No fue hasta principios del siglo XX con la recuperación demográfica, cuando la ciudad comenzó a revitalizarse. 
Actualmente, y gracias a su historia, Córdoba posee una importante riqueza cultural, que ha conservado durante siglos, convirtiéndose en una de las ciudades monumentales más importantes del mundo y uno de los destinos turísticos más atractivos.

La Unesco (Organización Cultural, Científica y Educacional de Naciones Unidas) reconoció en 1994 la importancia universal de los bienes históricos cordobeses, ampliando el título de Patrimonio de la Humanidad no sólo a la Mezquita Catedral, que ya tenía esta distinción desde 1984, sino también a todo el conjunto urbano que la rodea. Además, en diciembre de 2012, Córdoba recibió otro distintivo más: La Fiesta de Los Patios fue reconocida como Patrimonio Cultural Inmaterial de la Humanidad.

Por tanto, Córdoba cuenta con 3 inscripciones en la Lista del Patrimonio Mundial concedidas por la Unesco: La Mezquita Catedral (1984), el centro histórico que la rodea (1994) y la Fiesta de Los Patios (2012). Además, como el resto de España, disfruta del título de Patrimonio Cultural Inmaterial de la Humanidad concedido también al Flamenco (2010) y a la Dieta Mediterránea (2013).

La categoría de Patrimonio de la Humanidad se concede con el objeto de proteger, identificar y preservar el abolengo cultural o natural que se considera especialmente valioso. Ostentar este título comporta una serie de derechos y obligaciones de los que esta ciudad se ha hecho justa merecedora.

La Unesco define el Patrimonio como el legado que recibimos del pasado, lo vivimos en el presente y lo transmitimos al futuro.

Principales monumentos y lugares de interés de la ciudad, según la delegación de turismo del ayuntamiento de Córdoba:

Ruinas y palacio de Medina Azahara. (Bien de Interés Cultural, año 1923). Al pie del llamado monte de la Desposada se encuentran las ruinas del Conjunto Arqueológico Medina Azahara. Su construcción, iniciada en el año 936, se debe al primer califa de Al-Andalus, Abderramán III, en honor a su favorita Al Zahra. En el año 1010 fue saqueada e incendiada durante la guerra civil que desmembró al califato en los reinos de taifas.

La Mezquita. (BIC, 1882). Es el monumento más importante de todo el Occidente islámico y uno de los más asombrosos del mundo. En su historia se resume la evolución completa del estilo omeya en España, además de los estilos gótico, renacentista y barroco de la construcción cristiana.

Puente Romano. (BIC, 1931). Está compuesto por 16 arcos, ha sufrido muchas reformas y ha sido víctima de guerras y revueltas. Se cree que fue construido por el Emperador Augusto. En la primera mitad del puente se eleva una escultura de San Rafael, que data de 1651. Siempre está llena de flores y velas, con motivo de las peticiones de los cordobeses.

Torre de la Calahorra. (BIC, 1931) se trata de la torre defensiva más antigua de la ciudad. Fue construida por los musulmanes para guardar la entrada de la ciudad desde el Puente Romano. En la actualidad, la Torre alberga el Museo Vivo de Al-Andalus, una interesante propuesta de acercamiento a cristianos, judíos y musulmanes.

Alcázar de los Reyes Cristianos. (BIC, 1931). Fortaleza y palacio de sólidos muros, encierra en su interior gran parte de la evolución arquitectónica de Córdoba. Restos romanos y visigodos conviven con los de origen árabe en este majestuoso solar, ya que fue lugar predilecto de los distintos gobernantes de la ciudad. 
Sinagoga. (BIC, 1885). Única en Andalucía y tercera de las mejor conservadas de época medieval de toda España, la Sinagoga de Córdoba está situada en el barrio de la Judería. Construida entre los años 1314 y 1315 según las inscripciones halladas en el edificio, sirvió de templo hasta la definitiva expulsión judía.

Templo romano. (BIC, 2007) que data del siglo I d.C., es uno de los mejores conservados de esta época en la ciudad. Se trata de un templo próstilo, con seis columnas en la fachada, de planta rectangular y elevado sobre un podium al que se accede por una escalinata situada en el lado oriental. Frente a ésta se localiza un altar de grandes dimensiones, construido también sobre una plataforma artificial, junto al que hay indicios de la existencia de otra ara que aún no ha sido excavada. Los muros son de sillares de arenisca y algunas de las columnas se reconstruyeron a principios de los años sesenta del pasado siglo.

Torre de la Malmuerta, es una torre albarrana que se envuelve en la leyenda. La tradición popular asegura que el nombre de la torre se debe a la muerte de una noble dama cordobesa a manos de su marido celoso.

Calle de las Flores, es una de las calles más populares y turísticas de la ciudad de Córdoba. Se trata de un estrecho pasaje de arcos y suelos empedrados que desemboca en una bella plazoleta donde las macetas de geranios y claveles rodean al visitante.

Plaza del Potro. Situada en el barrio de la Ajerquía, debe su nombre a la fuente renacentista que la preside, cuyo principal elemento decorativo es la figura de un potro. Tradicionalmente fue lugar de compra-venta de ganado y de actividades artesanales, tal y como demuestra la famosa Posada del mismo nombre. Hoy en día acoge en uno de sus laterales los museos de Bellas Artes y Julio Romero de Torres.

Además, dos atractivos turísticos que pueden concitar el interés de los visitantes de la ciudad, y en general, de la península ibérica son:

Flamenco, es un estilo de música y danza propio de Andalucía, Extremadura y Murcia. Sus principales facetas son el cante, el toque y el baile, contando también con sus propias tradiciones y normas. En noviembre de 2010 la Unesco lo declaró Patrimonio Cultural Inmaterial de la Humanidad.

Fiesta Taurina. El origen de las corridas de toros en España hunde sus raíces en la cultura grecolatina que es introducida en el proceso de romanización. El culto al toro como divinidad y su sacrificio ritual está constatado en las civilizaciones minoica y otras del mediterráneo oriental desde al menos la edad del bronce.

Los monumentos nombrados anteriormente, son algunos de los mayores atractivos turísticos de la ciudad de Córdoba, es por ello, que resulta de interés conocer las preferencias de los turistas ante los mismos, y analizar en profundidad el grado de interés que por los mismos despierta entre sus visitantes.

\section{Metodología}

Se elaboró un instrumento de encuesta con 16 ítems, de los cuales 6 eran de respuesta abierta y el resto de opción múltiple. Los ítems del 1 al 15 tenían como objetivo recabar información sociológica del individuo, de los motivos que han inducido a la persona a visitar la ciudad y los medios empleados para ésta.

El último ítem nos da información sobre el interés que expresa el turista acerca de los principales atractivos turísticos de la ciudad. Éste se elaboró a partir de una escala Likert de cinco categorías, que ha sido usada en innumerables trabajos para medir 
actitudes y valoraciones, desde que fue presentada por Likert (1932). Los cinco valores de la escala Likert se codificaron con números de 1 a 5 de forma que el valor 1 se asignó a estar "nada interesado", mientras que el valor 5 se asignó a "estar muy interesado".

Se tomó como base para la elaboración de la encuesta, la utilizada por Cabrera (2008), para determinar el perfil de consumo de los servicios de la ciudad de Puebla, México. Se reformularon algunas preguntas, se eliminaron otras, y se adecuó la relativa al interés por los atractivos turísticos de la ciudad. Los atractivos por los que se preguntó en el ítem 16 fueron:

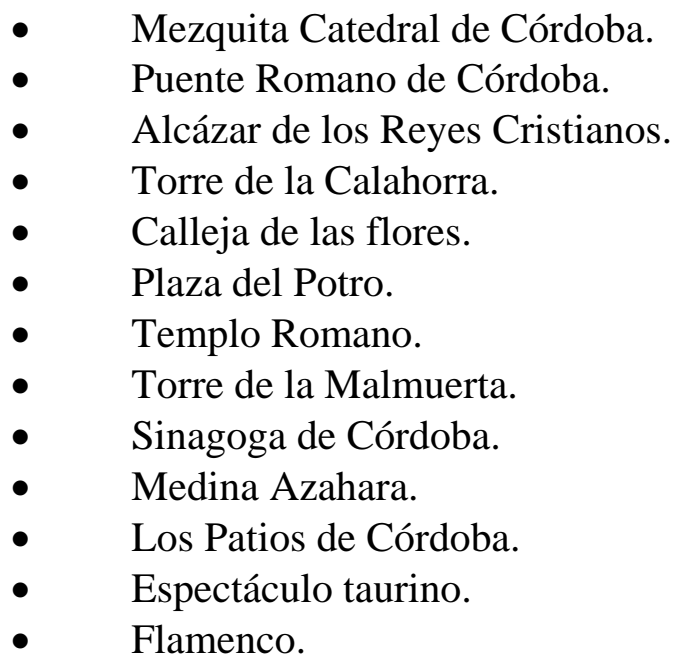

El orden en el que fue preguntado el interés por los distintos atractivos turísticos fue aleatorizado y cambiado en las diferentes copias de los cuestionarios, para evitar que el orden de presentación de los atractivos turísticos pueda influir en las respuestas dadas.

Una vez revisado el cuestionario y sometido a valoración de expertos, se aplicó a una muestra piloto de 50 individuos para medir la consistencia en las respuestas al interés mostrado por cada atractivo, dejando fuera, de la medición de ésta, el resto de ítems, ya que éstos valoran otros constructos relacionados con características sociodemográficas.

El estudio de la consistencia se realizó mediante el cálculo del alfa de Cronbach, propuesto por Cronbach (1951), para el conjunto formado por los ítems destinados a medir el grado de interés mostrado por los 13 atractivos turísticos. Una vez calculado éste, se analizó el cambio producido al eliminar uno de los ítems de estudio, de modo que un incremento en el valor del coeficiente tras la eliminación del ítem determinaría la inconsistencia de éste, respecto al resto.

Tras la obtención de resultados satisfactorios para el estudio de la consistencia, se amplió la muestra de estudio hasta un total de 454 individuos. Todas las encuestas fueron realizadas entre el 21 de diciembre de 2015 y el 5 de enero de 2016, en lugares de alta densidad de tránsito de turistas. Principalmente, en el casco antiguo de la ciudad, en diferentes puntos de la misma.

El instrumento fue redactado, también, en inglés y francés para facilitar la respuesta de la misma para no hispanohablantes.

Una vez obtenidas las respuestas a los distintos ítems, los datos fueron tabulados y tratados estadísticamente con el software SPSS, versión 23. Inicialmente, se realizó un 
análisis descriptivo unidimensional, y posteriormente a través de tablas de contingencia, se analizó el grado de asociación de las distintas variables observadas. Por último, se realizaron comparaciones entre las respuestas dadas de los distintos grupos de población, mediante el uso de test de hipótesis de Mann - Whitney y de Kruskall Wallis.

\section{Resultados}

El análisis de la consistencia arrojó un valor de alfa de Cronbach de 0.806, y la eliminación de cualquiera de elementos de valoración del interés, disminuiría el valor de éste.

La muestra estaba formada por 454 individuos, de los cuales el $71.74 \%$ eran de nacionalidad española, el 15.85 \% eran europeos no nacionales, y el resto no europeos. Lo que supone que menos de un $13 \%$ de los encuestados procedía de un país no europeo.

La paridad entre sexos es casi exacta, ya que el $52.72 \%$ de las personas encuestadas eran mujeres, mientras que el $47.28 \%$ restante eran hombres.

En cuanto a la edad de los entrevistados, la edad predominante era la comprendida entre los 25 y 44 años, representando este grupo casi la mitad del total, con un $45.68 \%$. Por detrás de éste se encuentra el grupo de personas con edades comprendidas entre los 45 y los 64 años, cuyo porcentaje asciende al $35 \%$.

Uno de los temas que surgen reiteradamente al hablar del turismo de la ciudad de Córdoba es el de la duración de la estancia en la ciudad. La más común, según los resultados de este estudio, es la comprendida entre 1 y 3 días, representando un porcentaje algo superior al $63 \%$. Si incluimos a todos los turistas cuya estancia es igual o inferior a una semana, este porcentaje supera el $90 \%$ de los consultados.

Toda esta información puede consultarse en la Figura 1.

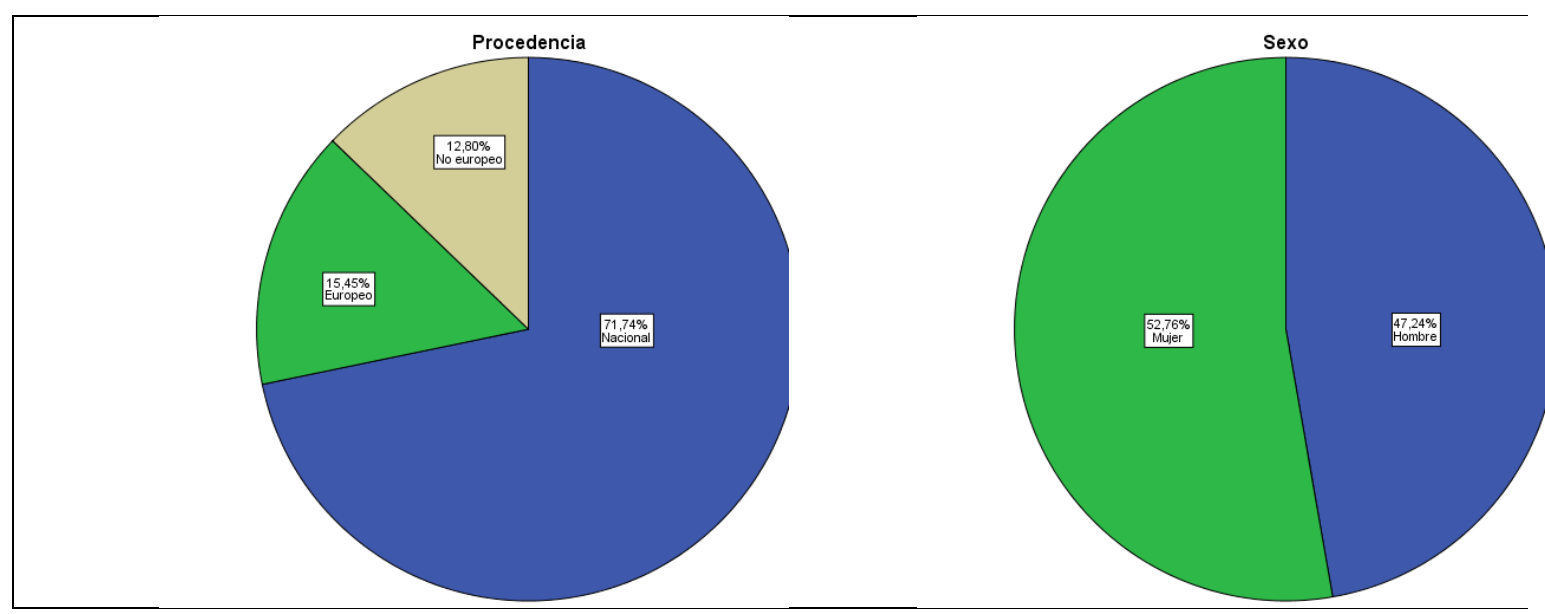




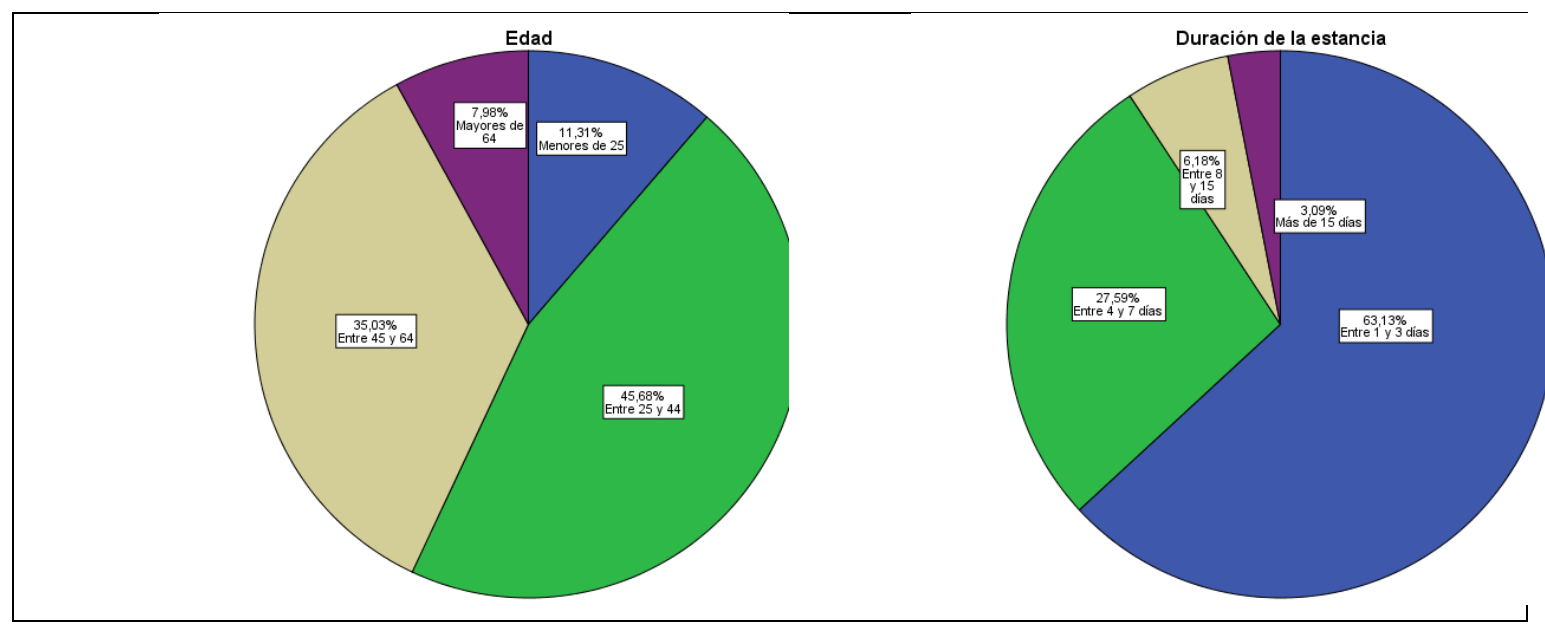

Figura 1.Información de la muestra. (Fuente: Elaboración propia)

Por otro lado, el motivo principal de la visita para el $47.6 \%$ de los encuestados fue "descanso y placer", seguido de la "cultura”, motivo principal para el $24.1 \%$ de los entrevistados.

Además, los factores que más influenciaron, a la hora de decantarse por la ciudad de Córdoba como destino turístico, fueron el conocimiento previo, con un 29 \%; y las recomendaciones de familiares y amigos con un $25.4 \%$

Las principales vías de acceso a la ciudad son la carretera y el tren. No en vano, el $48 \%$ de los turistas entrevistados se habían desplazado a la ciudad en coche, y el 32.3 \% lo había hecho en tren.

El análisis de la vía de reserva del viaje y del tiempo previo con el que realizó ésta, arrojó la siguiente información: sólo un tercio de los encuestados dejaron para la semana previa al viaje, la reserva del mismo, y el $62.8 \%$ lo gestionaron a través de internet.

En cuanto al alojamiento y al desplazamiento por la ciudad, el $64.7 \%$ de los entrevistados pernoctaron en hoteles, seguido del $14.1 \%$ que lo hizo en hostales y el $11.5 \%$ en casas de amigos y familiares. Sólo el $6.4 \%$ lo hizo en apartamentos de alquiler. De los primeros, el $78.14 \%$ lo hizo en hoteles de 3 o 4 estrellas, que son mayoritarios en la ciudad.

La cercanía de muchos de los atractivos de la ciudad y el elevado porcentaje de vías de uso exclusivamente peatonal del centro histórico de la ciudad, recomiendan realizar un gran número de rutas a pie, de hecho, un 56 \% de los turistas usaron esta vía para desplazarse por la ciudad, mientras que el $24.3 \%$ lo hizo en coche. 
Debido al carácter cualitativo de las variables, para describir el grado de interés de los 13 atractivos turísticos, se utilizó el valor mediano de éstos. El gráfico de medianas obtenido se muestra en la Figura 2.

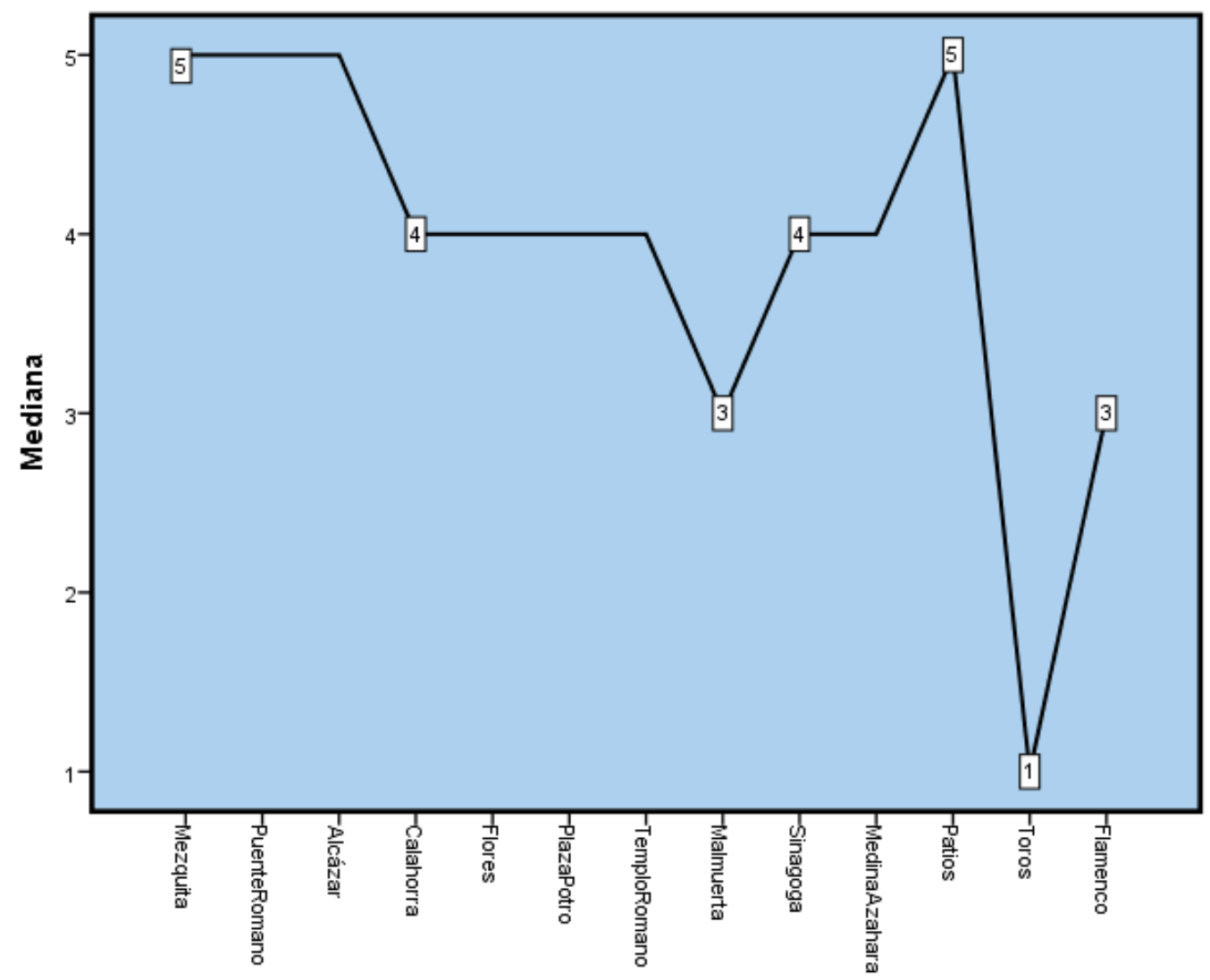

Figura 2. Grado de interés mediano de los atractivos turísticos. (Fuente: Elaboración propia)

Destaca positivamente el grado de interés mostrado por la Mezquita Catedral, el puente Romano, el Alcázar de los Reyes Cristianos y la fiesta de los patios, esta última declarada Patrimonio cultural inmaterial de la humanidad en el año 2012.

En el lado negativo, se encuentra destacado, de forma clara, el espectáculo taurino, por el que se expresa un reducido interés. Esta respuesta puede estar motivada, por un lado, por la fecha en la que se ha llevado a cabo la encuesta, ya que este espectáculo es estacional y tiene su momento álgido en mayo. Por otro lado, el movimiento antitaurino, cada vez más fuertemente arraigado en la sociedad, ha generado en los últimos tiempos un elevado rechazo a este espectáculo.

También destaca por el bajo valor de su mediana, aunque en menor medida, el grado de interés mostrado por la torre Malmuerta, separada de la zona turística principal y cerrada al público general, y el flamenco, también declarado Patrimonio cultural inmaterial de la humanidad desde el año 2010.

Al realizar la comparación del grado de interés, por sexos, observamos que no existen diferencias significativas salvo en cuatro de los atractivos turísticos, la calleja de las flores, la torre de la Calahorra, la plaza del Potro y la Sinagoga. Todas ellas 
recibieron un mayor grado de interés por parte de las mujeres, con probabilidades límite inferiores a 0.016 para pruebas de Mann - Whitney de comparación de distribuciones.

Al comparar el grado de interés en función de la procedencia del turista, observamos que los turistas nacionales muestran, ligeramente, un mayor grado de interés por la fiesta de los patios. Además, el grado de interés de los no europeos por el espectáculo taurino es mayor que para el resto de turistas, pero muestran un menor interés por el puente Romano y la torre de la Calahorra. Los resultados pueden observarse en la Figura 3.

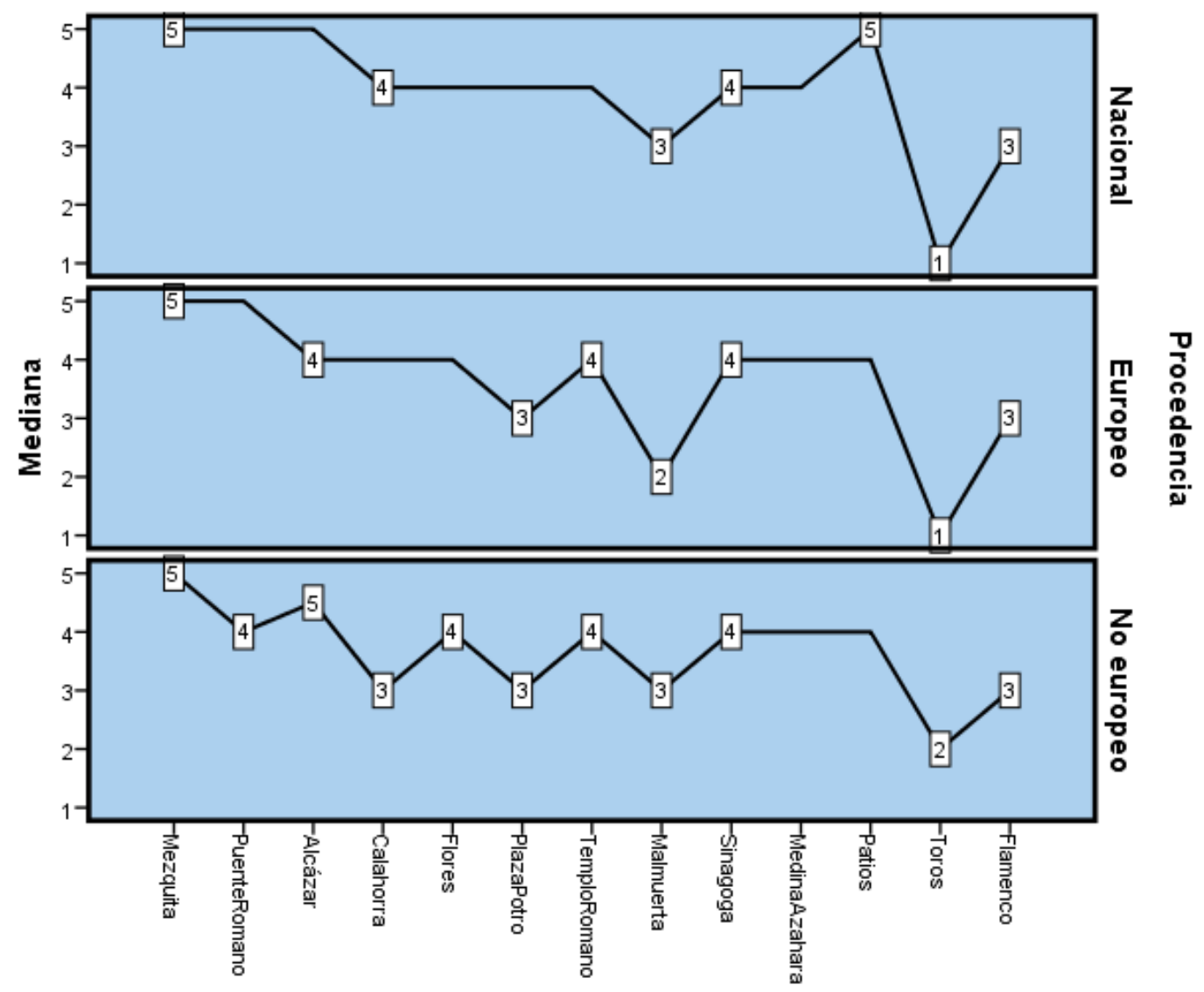

Figura 3. Grado de interés mediano de los atractivos turísticos según procedencia. (Fuente: Elaboración propia)

En cuanto a la edad, se hallaron diferencias significativas en el grado de interés mostrado por la Calahorra, de forma que los mayores de 64 años, mostraron mayor grado de interés que los que tenían una edad comprendida entre los 25 y los 44 años. De la misma forma, el grado de interés mostrado por los toros es significativamente superior en turistas mayores de 64 años que los que tienen edades comprendidas entre los 45 y los 64 años. Además, los menores de 25 años muestran un mayor grado de interés hacia el flamenco. Esto puede ser observado en la Figura 4. 


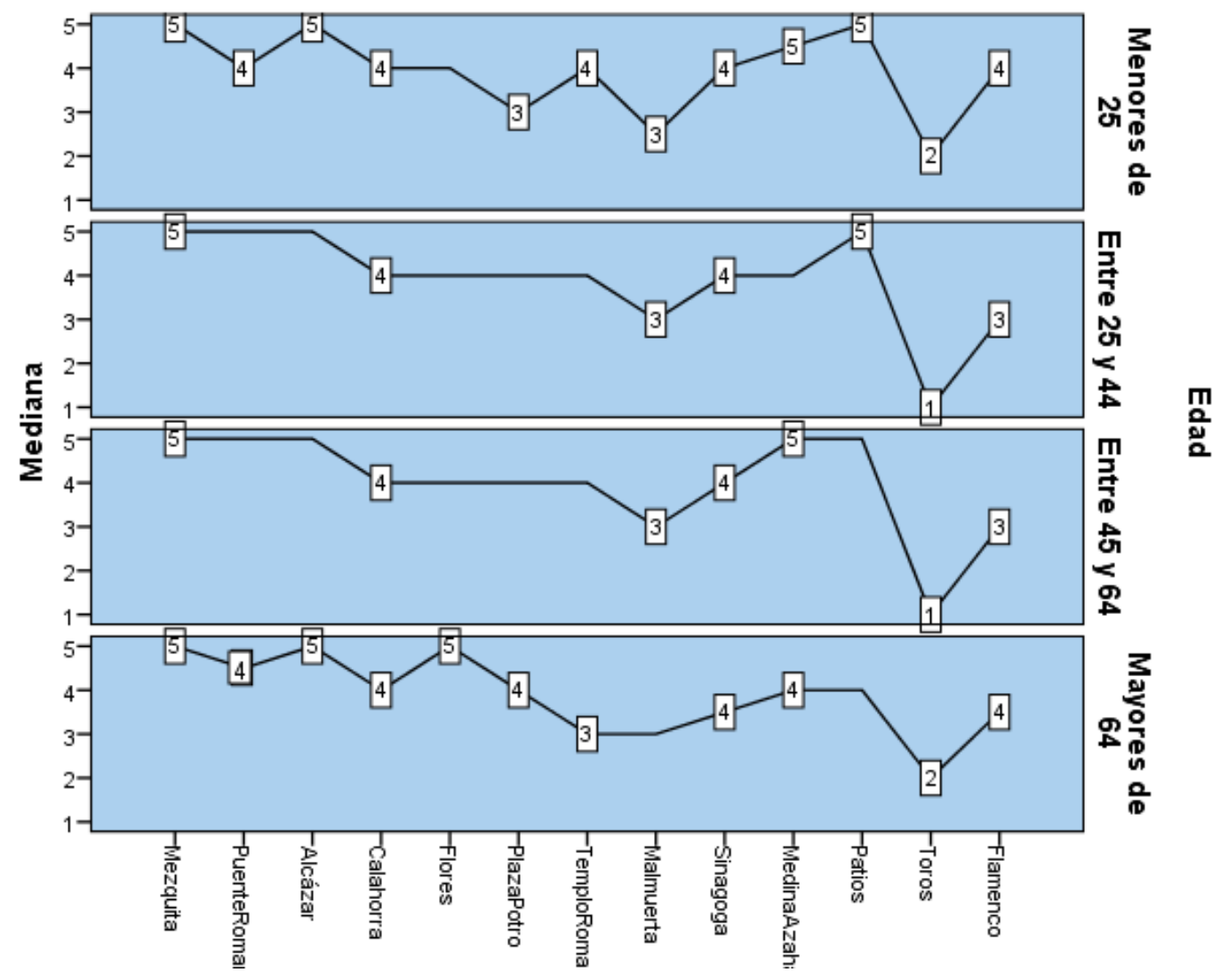

Figura 4. Grado de interés mediano de los atractivos turísticos según edad. (Fuente: Elaboración propia)

\section{Conclusiones y reflexiones}

Como hemos podido observar el perfil del turista que visita la ciudad de Córdoba tiene nacionalidad española y una edad comprendida entre 25 y 44 años de edad. Su estancia tiene una duración de entre 1 y 3 días, en los que se aloja en hoteles de tres o cuatro estrellas. La razón principal de su visita es el descanso y el placer, seguido de la cultura, y su motivación para visitar la ciudad es el conocimiento propio o la recomendación de amigos o familiares. Ha accedido a la ciudad a través de carretera, y se desplaza por la misma a pie. Ha realizado la reserva a través de internet, y con antelación suficiente. Los atractivos turísticos que mayor interés le despiertan son la Mezquita, el puente Romano, el Alcázar de los Reyes Cristianos, situados en el centro histórico, y la fiesta de los Patios.

Hemos observado escasas diferencias entre sexos, edad y procedencia en el interés mostrado por los trece atractivos analizados.

Cabe destacar el escaso interés por los toros, patrimonio cultural de España desde 2013 y llama la atención la baja puntuación del flamenco, declarado por la UNESCO patrimonio cultural inmaterial de la humanidad en el 2010.

Es importante destacar el reducido interés mostrado por los turistas hacia la torre Malmuerta, para la que podría plantearse un plan de actuación que la englobara dentro 
del conjunto monumental importante y de gran interés de la ciudad. Su lejanía del centro histórico y el hecho de estar cerrada al público dificultan su integración.

Es recomendable, además, una mayor promoción de la riqueza cultural de la ciudad ya que cabe recordar que sólo para un $24 \%$ de los turistas entrevistados, éste es el principal motivo de su visita.

\section{Bibliografía}

Burkart, A. J., \& Medlik, S. (1981). Tourism: past, present and future. Tourism: past, present and future.(Ed. 2).

Cabrera, M. E. G. (2008). Determinacion del perfil de consumo de servicios de apoyo turistico de los visitantes de la ciudad de Puebla.

Cronbach, L. J. (1951). Coefficient alpha and the internal structure of tests. psychometrika, 16(3), 297-334. Nacional.

De Arrillaga, J. I. (1955). El turismo en la economía nacional (Vol. 16): Editora

De la Torre Padilla, O. (1980). El turismo: fenómeno social: Fondo de cultura económica.

Hunziker, W., \& Krapf, K. (1942). Fundamentos de la Teoría General del Turismo. Universidad de Berna, Suiza.

Likert, R. (1932). A technique for the measurement of attitudes. Archives of psychology.

Mathieson, A., \& Wall, G. (1982). Tourism, economic, physical and social impacts: Longman. 